\title{
ELEgIBILIDAD POLÍTICA Y PROCESOS DE PAZ: UN ANÁLISIS A PARTIR DEL CASO COLOMBIANO
}

\author{
Political Eligibility and Peace \\ Processes: An Analysis Based on \\ the Colombian Case
}

\section{Elegibilidade política E PROCESSOS DE PAZ: UMA ANÁLISE A PARTIR DO CASO \\ COLOMBIANO}

YENNY ANDREA CELEMIN CAICEDO*

SERGIO JAVIER GARCIA**
* $\quad$ orcid.org/0000-0003-0540-2036. Universidad Jorge Tadeo Lozano, Colombia. yennya.celeminc@utadeo.edu.co
** orcid.org/0000-0001-8425-0143. Consejo Nacional Electoral, Colombia. sjgarcia@cne.gov.co

RECIBIDO: 10 DE AGOSTO DE 2018. ENVÍO A PARES: 12 DE AGOSTO DE 2018 APRoBAdo POR PARES: 12 DE SEPTIEMBRE DE 2018. ACEPTADO: 12 DE SEPTIEMBRE DE 2018

DOI: 10.5294 /DIKA.2019.28.1.5

PARA CITAR ESTE ARTÍCULO / TO REFERENCE THIS ARTICLE / PARA CITAR ESTE ARTIGO

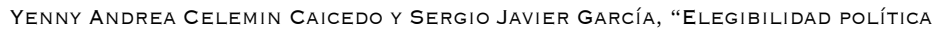
Y PROCESOS DE PAZ: UN ANÁLISIS A PARTIR DEL CASO COLOMBIANO”, EN DIKAION 28, 1 


\section{RESUMEN}

El Acuerdo de Paz celebrado entre el Estado colombiano y las Fuerzas Armadas Revolucionarias de Colombia (FARC) ha redefinido una de las causales de mayor estabilidad en el régimen de inhabilidades para hacerse elegir como representante en Colombia. Este régimen imponía como obstáculo para ostentar la calidad de elegido el haber sido sujeto de sanciones a penas privativas de la libertad por la comisión de delitos que no tuvieran el carácter de delitos políticos o culposos. Sin embargo, a partir del Acuerdo de Paz y de las normas que lo han venido desarrollando se ha facultado a los excombatientes y a otros actores del proceso para el ejercicio del sufragio activo. Esta modificación hace parte de los arreglos para compartir el poder que se crearon como consecuencia de este proceso de negociación. El presente texto tiene el propósito de describir y analizar estas modificaciones y de poner en evidencia algunos de los problemas interpretativos producidos por estos cambios.

\section{PALABRAS CLAVE}

Elegibilidad política; inhabilidad por condenas penales; proceso de paz de Colombia; acuerdos para compartir el poder. 


\section{ABSTRACT}

The Peace Agreement signed between the Colombian state and the Revolutionary Armed Forces of Colombia (FARC, from its initials in Spanish) has redefined one of the more stable grounds for disqualification to be elected as a representative in Colombia. This disqualification system prevents individuals who have been subject to prison sentences for committing crimes other than political or negligent crimes from being elected. However, due to the Peace Agreement and the regulations to implement it, former combatants and other actors of the process have been empowered to exercise active suffrage. This modification is part of the power-sharing arrangements that derived from this negotiation process. This paper aims to describe and analyze these modifications and to highlight some of the interpretive problems produced by these changes.

\section{KEYWORDS}

Political eligibility; ineligibility based on criminal records; Colombian's Peace Agreement, power-sharing agreements. 


\section{RESUMO}

O Acordo de Paz celebrado entre o Estado colombiano e as Forças Armadas Revolucionárias da Colômbia (FARC) redefiniu uma das causas de maior estabilidade no regime de incompatibilidades para ser eleito como representante na Colômbia. Esse regime impunha, como obstáculo para ser eleito, que o candidato tivesse sido sujeito de sanções a penas privativas da liberdade pela comissão de delitos que não tivessem caráter de delitos políticos ou culposos. No entanto, a partir do Acordo de Paz e das normas que foram se desenvolvendo, facultou-se o exercício do sufrágio ativo aos ex-combatentes e a outros atores do processo. Essa modificação faz parte dos ajustes que foram criados como consequência desse processo de negociação para compartilhar o poder. O presente texto tem o propósito de descrever e analisar essas modificações e colocar em evidência alguns dos problemas interpretativos produzidos por tais mudanças.

\section{PALAVRAS-CHAVE}

Elegibilidade politica; incapacidade para condenações penais; Processo de $\mathrm{Paz}$ na Colômbia; Acordos para compartilhar poder. 
SumARio: METOdología. INTROducción. 1. El RÉgimen de inhabilidades COMO GaRANTÍA DEL PROCESO DE REPRESENTACIÓN POLÍTICA EN COLOMBIA. 2. LA AUSENCIA DE CONDENAS PENALES COMO REQUISITO DE ELEGIBILIDAD POLÍTICA. 3. LAS MODIFICACIONES AL RÉGIMEN DE INHABILIDADES PARA SER ELEGIDO CONGRESISTA COMO CONSECUENCIA DEL PROCESO DE PAZ. 3.1. EL CONTEXTO DEL PROCESO DE PAZ. 3.2. LA PROMOCIÓN DE LAS IDEAS POLÍTICAS DE LA ORGANIZACIÓN EN PROCESO DE TRANSICIÓN COMO UN ACUERDO PARA COMPARTIR EL PODER EN VIRTUD DEL PROCESO DE PAZ. 3.3. ¿A QUIÉN SE HABILITA PARA CONFORMAR LOS NUEVOS ESCENARIOS CREADOS EN VIRTUd del ACUERdo de PAz, para compartir el poder? 4. El ACuerdo DE PAZ Y LOS ESCENARIOS DE ESTABILIDAD Y DE CAMBIO DE LA INHABILIDAD POLÍTICA POR CONDENA PENAL. 5. ALGUNOS PROBLEMAS JURÍdicos E INTERPRETATIVOS DEL CAMBIO DE LA INHABILIDAD POLÍTICA POR CONDENA PENAL A PARTIR DEL PROCESO DE PAZ. 6. CONCLUSIÓN. BIBLIOGRAFÍA.

\section{Metodología}

Para alcanzar los objetivos propuestos, el presente trabajo estudia distintos acuerdos de paz a fin de examinar la naturaleza de las cláusulas para compartir el poder establecidas en diversos procesos de paz. Finalmente, el artículo se centra en el caso colombiano. Para el estudio de caso se parte de un análisis directo de documentos normativos como el Acuerdo de Paz de La Habana, y decisiones legislativas y jurisprudenciales sobre la materia que son revisadas a partir de una metodología histórico-hermenéutica de investigación, que parte de la centralidad de la actividad interpretativa en las tareas propias de la disciplina jurídica.

\section{INTRODUCCIÓN}

Uno de los aspectos centrales sobre los que se fundamentan los sistemas democráticos contemporáneos se manifiesta en la existencia de una división del trabajo entre los elegidos y los electores para la toma de las decisiones políticas. De esta manera, a pesar que, de forma universal, se garantiza a todas las personas un derecho humano para que ellas puedan asumir cualquiera de estos roles, ${ }^{1}$ los sistemas democráticos establecen una serie de reglas que limitan ambas prerrogativas.

Dentro de las condiciones para participar politicamente en calidad de elector, el sistema colombiano impone ciertas restricciones por diversos motivos: i) en razón

1 Declaración Universal de Derechos Humanos, artículo 21: “1. Toda persona tiene derecho a participar en el gobierno de su país, directamente o por medio de representantes libremente escogidos. 2. Toda persona tiene el derecho de acceso, en condiciones de igualdad, a las funciones públicas de su país. 3. La voluntad del pueblo es la base de la autoridad del poder público; esta voluntad se expresará mediante elecciones auténticas que habrán de celebrarse periódicamente, por sufragio universal e igual y por voto secreto u otro procedimiento equivalente que garantice la libertad del voto". 
de la edad, ${ }^{2}$ ii) en virtud del origen nacional, ${ }^{3}$ iii) por cuenta de la función que se cumple dentro de la estructura del Estado, ${ }^{4}$ iv) en razón de la imposición de medidas sancionatorias del carácter accesorio, tales como la interdicción en el ejercicio de derechos o funciones públicas. ${ }^{5}$

Por su parte, el ejercicio del rol de elegido impone una serie de restricciones y condicionamientos que son mucho más exigentes. Estas limitaciones, en primer término, contienen todas las exigencias para ejercer el rol de elector descritas anteriormente, con algunas cualificaciones adicionales. ${ }^{6}$ Pero también hay otros requisitos que hacen más complejo el ejercicio de esta arista del derecho a la participación política.

En primer lugar, el ordenamiento jurídico obliga, a quienes pretendan hacerse elegir, a inscribirse en los procesos electorales a través de los partidos, movimientos políticos o grupos significativos de ciudadanos. En este orden de ideas, ningún ciudadano puede presentarse a un proceso de naturaleza electoral sin contar con el aval previo de una organización o colectividad política en virtud de lo establecido en el artículo 2 de la Ley 130 de $1994 .^{7}$

2 Constitución Política de Colombia, artículos 98 y 99: "Artículo 98. La ciudadanía se pierde de hecho cuando se ha renunciado a la nacionalidad, y su ejercicio se puede suspender en virtud de decisión judicial en los casos que determine la ley.

Quienes hayan sido suspendidos en el ejercicio de la ciudadanía, podrán solicitar su rehabilitación. Parágrafo. Mientras la ley no decida otra edad, la ciudadanía se ejercerá a partir de los dieciocho años". "Artículo 99. La calidad de ciudadano en ejercicio es condición previa e indispensable para ejercer el derecho de sufragio, para ser elegido y para desempeñar cargos públicos que lleven anexa autoridad o jurisdicción".

3 Constitución Política de Colombia, artículo 100: "Los extranjeros disfrutarán en Colombia de los mismos derechos civiles que se conceden a los colombianos. No obstante, la ley podrá, por razones de orden público, subordinar a condiciones especiales o negar el ejercicio de determinados derechos civiles a los extranjeros.

Así mismo, los extranjeros gozarán, en el territorio de la República, de las garantías concedidas a los nacionales, salvo las limitaciones que establezcan la Constitución o la ley.

Los derechos políticos se reservan a los nacionales, pero la ley podrá conceder a los extranjeros residentes en Colombia el derecho al voto en las elecciones y consultas populares de carácter municipal o distrital".

4 Constitución Política de Colombia, artículo 219: "La Fuerza Pública no es deliberante; no podrá reunirse sino por orden de autoridad legitima, ni dirigir peticiones, excepto sobre asuntos que se relacionen con el servicio y la moralidad del respectivo cuerpo y con arreglo a la ley.

Los miembros de la Fuerza Pública no podrán ejercer la función del sufragio mientras permanezcan en servicio activo, ni intervenir en actividades o debates de partidos o movimientos políticos".

$5 \quad$ Ley 599 de 2000, artículo 52. "Las penas accesorias. Las penas privativas de otros derechos, que pueden imponerse como principales, serán accesorias y las impondrá el Juez cuando tengan relación directa con la realización de la conducta punible, por haber abusado de ellos o haber facilitado su comisión, o cuando la restricción del derecho contribuya a la prevención de conductas similares a la que fue objeto de condena.

En la imposición de las penas accesorias se observará estrictamente lo dispuesto en el artículo 59. En todo caso, la pena de prisión conllevará la accesoria de inhabilitación para el ejercicio de derechos y funciones públicas, por un tiempo igual al de la pena a que accede y hasta por una tercera parte más, sin exceder el máximo fijado en la Ley, sin perjuicio de la excepción a que alude el inciso 2 del artículo 51".

1226 Por ejemplo, una edad minima para ocupar los cargos.

7 Sobre el particular es importante reseñar la decisión de la Corte Interamericana de Derechos Humanos, Caso Castañeda Gutman vs. México, de 6 de agosto de 2008, Excepciones Preliminares, Fondo, Reparaciones y Costas, Serie C, núm. 184. En esta decisión, el demandante acudió a la ins- 
Adicionalmente, la posibilidad de inscribirse a estas contiendas electorales con el propósito de ejercer un cargo de representación popular está mediada por el cumplimiento de otra serie de condiciones establecidas en la Constitución Política y la ley. Una de estas condiciones es la de respetar el régimen de inhabilidades para hacer parte de las corporaciones públicas, tales como el Congreso de la República.

En relación con estas condiciones es preciso señalar que el régimen de inhabilidad para ser elegido como congresista en Colombia ha gozado de relativa estabilidad en nuestro ordenamiento constitucional. Muchas de las inhabilidades hoy presentes en el texto de la Constitución han pervivido desde los textos constitucionales que rigieron a Colombia durante el siglo XIX. ${ }^{8}$ Esta estabilidad ha generado que tales causales hayan sido objeto de una intensa delimitación e interpretación por parte del derecho jurisprudencial proferido por las altas Cortes en Colombia, especialmente, por la Sección Quinta del Consejo de Estado.

Sin embargo, en la actualidad, dicha estabilidad es objeto de una intensa disputa. Lo anterior, en virtud del Acuerdo de Paz para resolver el conflicto armado interno suscrito entre el Estado colombiano y el grupo insurgente Fuerzas Armadas Revolucionarias de Colombia-Ejército del Pueblo (FARC-EP), en el que se redefine una de las causales del régimen de inhabilidades en Colombia.

Este régimen imponía como obstáculo para ostentar la calidad de elegido el haber sido sujeto de sanciones de penas privativas de la libertad por la comisión de delitos que no tuvieran el carácter de políticos o culposos. Sin embargo, el Acuerdo de Paz ha consagrado la necesidad de efectuar una serie de reformas constitucionales y legales para facultar a los miembros del grupo alzado en armas a ejercer al derecho de representar a los colombianos en el Congreso. Estas modificaciones hacen parte de los arreglos para compartir el poder que se crearon como consecuencia del proceso de negociación.

No obstante, aquí se va a sostener que estas modificaciones presentan algunos inconvenientes importantes. Especialmente, porque mediante ellas se establece una diferenciación desproporcionada entre los excombatientes que cometieron las infracciones más graves al derecho internacional humanitario (DIH) con ocasión del conflicto armado, y los excombatientes que con sus conductas no lesionaron estos principios de manera tan grave, pero que por haber sido beneficiaros de indultos conservan a perpetuidad una limitación de su derecho a la elegibilidad política. Esta limitación impide a los desmovilizados indultados por el presidente de la República por no haber cometido delitos contra el DIH hacer parte de los

tancia internacional ante la negativa de la autoridad electoral mexicana de inscribirlo como candidato a las elecciones presidenciales por no tener el respaldo de un partido político, pues pretendía presentarse como candidato individual. De acuerdo con su solicitud, esta negativa vulneraba su derecho a la participación política y su libertad de asociación. La Corte falló negando las pretensiones de Castañeda, pero el caso se convierte en un antecedente interesante frente a la discusión de las limitaciones a la universalidad de los derechos políticos en el contexto latinoamericano.

8 La Constitución Nacional de 1886, en su artículo 100, señalaba lo siguiente: "Para ser elegido Representante se requiere ser ciudadano en ejercicio, no haber sido condenado por delito que merezca pena corporal, y tener más de veinticinco años de edad”. 
escenarios para compartir el poder que fueron creados como consecuencia del proceso de paz. Igualmente, con esta modificación se lesionan desproporcionadamente los derechos a la participación política de otros ciudadanos colombianos no involucrados en el conflicto armado.

Para sustentar esta tesis este artículo está dividido en varias partes. En la primera parte se hace una caracterización del régimen de inhabilidades para la elegibilidad política en Colombia. A partir de esta caracterización, el artículo se enfoca en la restricción relacionada con la prohibición de elegibilidad por cuenta de la existencia de condenas penales, y en los cambios que esta prohibición ha soportado como consecuencia del proceso de paz. En la última parte, se establecen las problemáticas de interpretación de estas normas de transición en el contexto colombiano.

\section{EL RÉGIMEN DE INHABILIDADES COMO GARANTÍA DEL PROCESO DE REPRESENTACIÓN POLÍTICA EN COLOMBIA}

Previo a abordar el análisis de fondo, conviene ubicar al lector con algunas precisiones conceptuales. Aquí se parte de la máxima según la cual, las constituciones politicas deben entenderse como la forma en que se implanta, funciona y se transmite el poder politico. Nuestra Carta de 1991, y las leyes que la complementan, han establecido condiciones para acceder a ese poder y participar de él. ${ }^{9}$

La elegibilidad política y su contrario, la inelegibilidad política, constituyen los pilares sobre los que se ha erigido la existencia de estas condiciones que regulan la transmisión del poder político. A partir de ellas se ha edificado el derecho fundamental de participación política de elegir y ser elegido, en especial la capacidad para ser elegido. ${ }^{10}$ La elegibilidad politica puede definirse como

... la parte de nuestra legislación que establece las calidades para ser elegible. Así mismo, elegible es el ciudadano que tiene la capacidad legal requerida para ser designado para los cargos públicos cuyo nombramiento se hace mediante el sufragio. Es también la persona que reúne los requisitos para ser elegido para algún cargo o destino público provisto mediante los mecanismos electorales. ${ }^{11}$

Por su parte, la inelegibilidad politica puede entenderse como:

La denominación no elegibilidad, también conocida como inelegibilidad, es el conjunto de normas especialmente constitucionales que excluyen a determinados ciudadanos de la posibilidad de ser elegidos por motivos previstos por la Carta. ${ }^{12}$

9 Carlos Ariel Sánchez Torres, Derecho electoral colombiano, Bogotá, Legis, 1997, p. 211.

10 Héctor Enrique Rey Moreno, La inelegibilidad. Su tratamiento en el sistema jurídico colombiano, Bogotá, Grupo Editorial Ibáñez, 2008, p. 23.

11 José Ignacio Vives EcheverRíA, Tratado de derecho electoral colombiano, Bogotá, Temis, 1984, p. 235.

12 Ibid., p. 245. 
Para el objeto de este artículo interesa la elegibilidad politica o, desde su perspectiva negativa, la inelegibilidad política predicable a partir de la configuración de las inhabilidades previstas para ejercer cargos de elección popular, en especial la inhabilidad por condena judicial. Limitación que resulta de gran importancia en la medida en que tiene por objeto garantizar la transparencia y el buen desarrollo del proceso electoral para excluir de él a todos aquellos ciudadanos que por su particular posición, situación o influencia pueden perturbar, incidir o persuadir la libre voluntad del electorado. ${ }^{13}$

La consagración de un régimen de inhabilidades para restringir el derecho a la participación politica de ciertas personas que aspiran a hacerse elegir en los procesos electorales se constituye en una garantía al proceso de representación política. En el ordenamiento jurídico colombiano se define la inhabilidad como todo acto o situación que invalide la elección de congresista o impide serlo. Esta definición de gran vaguedad debe ser complementada con el conjunto de restricciones expresamente consagradas en el artículo 179 de la Constitución Política, conocido como el régimen de inhabilidades. Este régimen tiene ciertas características importantes que han sido determinadas por la jurisprudencia nacional.

A partir de estas delimitaciones se ha sostenido, en primer lugar, que las inhabilidades deben ser de creación constitucional o legal. En este orden de ideas, solo mediante los procedimientos de creación de normas jurídicas, en los que se discuten ampliamente las cargas y los beneficios de imponer limitaciones a los derechos, como es el caso de la participación política, es posible que se configure una inhabilidad. ${ }^{14}$

Una segunda característica del régimen de inhabilidades está dada por su naturaleza sancionatoria. De esta manera, la transgresión de las limitaciones establecidas por la Constitución o la ley por parte de quienes pretendan ejercer el rol de elegidos dentro del proceso de representación conlleva diversas sanciones jurídicas.

En primer término, este tipo de transgresiones habilita a la autoridad electoral de Colombia, el Consejo Nacional Electoral, a revocar la inscripción de quien, en calidad de candidato, pretenda ser partícipe de un proceso electoral (CP, art. 265, núm. 12).

Igualmente, esta naturaleza sancionatoria también se refuerza en la posibilidad con la que cuenta cualquier ciudadano de incoar la acción de pérdida de investidura, si de forma posterior a la elección se demuestra el incumplimiento del

13 Héctor Enrique Rey Moreno, La inelegibilidad. Su tratamiento en el sistema jurídico colombiano, ob. cit., p. 25.

14 No obstante, la Corte Constitucional estableció en su jurisprudencia temprana que para la determinación de un régimen de inhabilidades no se requería del trámite de ley estatutaria. Por lo tanto, de acuerdo con el alto tribunal, el legislador ordinario puede imponer este tipo de restricciones. Eso sí, atendiendo a criterios de razonabilidad y proporcionalidad de la medida que afecta la elegibilidad politica (Corte Constitucional, Sentencia C-373 de 1995). 
régimen inhabilidades. La sanción aparejada por la pérdida de investidura conlleva la imposibilidad absoluta de volverse a hacer elegir nuevamente en un cargo de estas características. ${ }^{15}$

Pero, por la gravedad y magnitud de la sanción por pérdida de investidura, la jurisprudencia ha establecido que las inhabilidades tienen carácter taxativo. Esta situación excluye, entonces, la posibilidad de realizar una imposición analógica de las consecuencias dispuestas en una inhabilidad a supuestos de hechos parecidos, pero no idénticos, a los consagrados de manera literal en la Constitución o en la ley. Una tercera característica de este régimen está ligada a la existencia de una pluralidad de criterios para la configuración de las conductas que son calificadas como inhabilitantes. Estos criterios se constituyen en los límites que buscan evitar la depravación del proceso de representación política. La tabla 1 incorpora las distintas causales de inhabilidad establecidas por la Constitución Política de Colombia.

\section{Tabla 1. Régimen de inhabilidades para ser congresista (art. 179 de la CP)}

\begin{tabular}{|c|c|c|c|}
\hline $\begin{array}{l}\text { Mérito como requisito de } \\
\text { elegibilidad a los cargos } \\
\text { públicos }\end{array}$ & $\begin{array}{c}\text { Garantía del derecho a la } \\
\text { igualdad }\end{array}$ & $\begin{array}{l}\text { Evitar la realización } \\
\text { de conductas } \\
\text { autointeresadas }\end{array}$ & $\begin{array}{l}\text { Evitar la realización } \\
\text { de conductas opuestas } \\
\text { a los intereses de los } \\
\text { representados }\end{array}$ \\
\hline $\begin{array}{l}\text { Inhabilidad para quienes } \\
\text { hayan sido condenados } \\
\text { en cualquier época por } \\
\text { sentencia judicial, a pena } \\
\text { privativa de la libertad, por } \\
\text { delitos distintos a los de } \\
\text { carácter político o culposo } \\
\text { (art. 179, núm. 1) }\end{array}$ & $\begin{array}{l}\text { Inhabilidad por la exis- } \\
\text { tencia de vínculos por } \\
\text { matrimonio, o unión per- } \\
\text { manente, o de parentesco } \\
\text { en tercer grado de con- } \\
\text { sanguinidad, primero de } \\
\text { afinidad, o único civil, con } \\
\text { funcionarios que ejerzan } \\
\text { autoridad civil o politica } \\
\text { (art. } 179 \text {, núm. 5) }\end{array}$ & $\begin{array}{l}\text { Haber intervenido en ges- } \\
\text { tión de negocios ante en- } \\
\text { tidades públicas, o en la } \\
\text { celebración de contratos } \\
\text { con ellas en interés pro- } \\
\text { pio, o en el de terceros, o } \\
\text { quienes hayan sido repre- } \\
\text { sentantes legales de en- } \\
\text { tidades que administren } \\
\text { tributos o contribuciones } \\
\text { parafiscales, dentro de los } \\
\text { seis meses anteriores a la } \\
\text { fecha de la elección (art. } \\
\text { 179, núm. 3) }\end{array}$ & $\begin{array}{l}\text { Tener una nacionalidad } \\
\text { distinta a la colombiana } \\
\text { excepto si se ostenta la } \\
\text { calidad de los colombianos } \\
\text { por nacimiento (art. 179, } \\
\text { núm. 7) }\end{array}$ \\
\hline $\begin{array}{l}\text { Inhabilidad para quienes } \\
\text { hayan sufrido la muerte } \\
\text { politica por haber perdido } \\
\text { la investidura (art. 179, } \\
\text { núm. 4) }\end{array}$ & $\begin{array}{l}\text { Haber ejercido, como em- } \\
\text { pleados públicos, jurisdic- } \\
\text { ción o autoridad política, } \\
\text { civil, administrativa o mi- } \\
\text { litar, dentro de los doce } \\
\text { meses anteriores a la fecha } \\
\text { de la elección (art. 179, } \\
\text { núm. 2) }\end{array}$ & & \\
\hline
\end{tabular}

15 Señala la Corte Constitucional, en la Sentencia SU-424 de 2016, respecto de esta figura: "La pérdida de investidura es una acción pública de carácter sancionatorio prevista en la Constitución y la ley, que tiene como finalidad castigar a los miembros de las corporaciones públicas que incurran en conductas consideradas reprochables por ser incompatibles con la dignidad del cargo que ostentan. En ese orden de ideas, se trata de un juicio sancionatorio, que se efectúa en ejercicio del ius puniendi del Estado, previsto por el Legislador como un procedimiento jurisdiccional a cargo del juez contencioso administrativo -la Sala Plena del Consejo de Estado-, quien hace un juicio de reproche sobre un comportamiento. Esta figura jurídica comporta un juicio ético, que exige de los representantes elegidos por el pueblo un comportamiento recto, pulcro y transparente. En efecto, el juez de pérdida de investidura juzga a los miembros de los cuerpos colegiados a partir de un código de conducta previsto en la Constitución que deben observar en razón del valor social y político de la investidura que ostentan". 


\begin{tabular}{|c|c|c|c|}
\hline $\begin{array}{c}\text { Mérito como requisito de } \\
\text { elegibilidad a los cargos } \\
\text { públicos }\end{array}$ & $\begin{array}{c}\text { Garantía del derecho a la } \\
\text { igualdad }\end{array}$ & $\begin{array}{c}\text { Evitar la realización } \\
\text { de conductas } \\
\text { autointeresadas }\end{array}$ & $\begin{array}{c}\text { Evitar la realización } \\
\text { de conductas opuestas } \\
\text { a los intereses de los } \\
\text { representados }\end{array}$ \\
\hline & $\begin{array}{c}\text { Inhabilidad por tener vincu- } \\
\text { lo de matrimonio, o unión } \\
\text { permanente, o parentesco } \\
\text { dentro del tercer grado de } \\
\text { consanguinidad, segundo } \\
\text { de afinidad, o primero civil, } \\
\text { y se inscriban por el mismo } \\
\text { partido, movimiento o gru- } \\
\text { po para elección de cargos, } \\
\text { o de miembros de corpora- } \\
\text { ciones públicas que deban } \\
\text { realizarse en la misma fecha } \\
\text { (art. 179, núm. 6) }\end{array}$ & \\
\hline
\end{tabular}

Fuente: elaboración propia con base en el artículo 179 de la CP.

Una de las causales incluidas en el régimen de inhabilidades en Colombia establece la limitación de carácter definitivo y perpetuo para los ciudadanos que, por haber sido objeto de condenas políticas, no cuenten con el mérito suficiente para ostentar la calidad de representantes en el proceso de autorización electoral. A continuación se reflexiona sobre esta causal de inhabilitación política y los impactos de su configuración en el proceso de paz.

\section{LA Ausencia de CONDENAS PENALES COMO REQUISITO DE ELEGIBILIDAD POLÍTICA}

El mérito como criterio que limita la elegibilidad política puede rastrearse incluso desde el nacimiento de la democracia representativa como forma de Gobierno. Señala Manin, frente a las cualificaciones exigidas a los legisladores en los debates del constitucionalismo norteamericano:

El 26 de julio de 1787, George Mason propuso una moción solicitando que se diesen instrucciones al Comité de Selección (el órgano que preparaba el trabajo de las sesiones plenarias) para que concibiese una cláusula exigiendo algunas cualificaciones de bienes raíces y de ciudadanía a los miembros de la legislatura y descalificase a personas que no tuviesen sus cuentas en orden o estuviesen en deuda con los Estados Unidos. Durante el debate Madison citó el ejemplo de los requisitos parlamentarios adoptados en Inglaterra durante el reinado de la reina Ana, que dijo "recibieron la aprobación universal". Morris respondió que prefería cualificaciones para ejercer el derecho al sufragio. Madison sugirió que había que suprimir la palabra bienes raíces de la moción de Mason, señalando que la posesión de tierras no era señal de verdadera riqueza. ${ }^{16}$

16 Bernard Manin, Los principios del gobierno representativo, Madrid, Alianza, 2008, pp. 131 y ss. 
En el ordenamiento jurídico colombiano este requisito se expresa en dos causales: la primera está contenida en el numeral 4 del artículo 179 que prohíbe a quienes hayan sido sancionados con la pérdida de investidura el postularse nuevamente a procesos electorales como representantes. Igualmente, el numeral 1 de esta norma constitucional estatuye una inhabilidad por condenas penales siempre y cuando esta condena no corresponda a la realización de delitos políticos y culposos.

En relación con esta última causal, es preciso señalar que, por cuenta de su estabilidad en nuestro ordenamiento jurídico, la autoridad jurisdiccional ha venido delimitando el sentido de esta inhabilidad a través de variadas decisiones jurisprudenciales. En primer lugar, el Consejo de Estado ha señalado que el término condena establecido en la norma constitucional está redactado de forma genérica. Por este motivo, la inhabilidad establecida en este artículo es una sanción también aplicable a personas que han sido condenadas por este tipo de penas en cualquier tiempo, incluso en el extranjero. ${ }^{17}$

De todas formas, el Consejo de Estado ha establecido que, cuando se trata de condenas en el exterior, los delitos por los cuales se impone la pena deben aparecer tipificados como tales en la legislación de nuestro país:

... en la hipótesis de la condena a pena privativa de la libertad por un delito que no exista en Colombia, y como tal, resulte extraño a los patrones culturales y éticos que informan nuestra institucionalidad, la misma no sería admisible como sustento de la causal examinada cuya razón de existencia es la salvaguarda de dichos patrones culturales (jurídicos) y éticos. ${ }^{18}$

Un segundo aspecto que es importante destacar en relación con la forma como el derecho jurisprudencial ha interpretado el numeral 1 del artículo 179 de la Constitución tiene que ver con el carácter definitivo que debe tener la sentencia judicial que pretenda limitar la elegibilidad politica. Al respecto, la jurisprudencia ha sido enfática en señalar que la notificación y la ejecutoria de la sentencia condenatoria son factores clave de validez para posibilitar la aplicación de la inhabilidad mencionada. Es decir, si la sentencia no ha sido notificada en debida

17 Esta precisión en relación con la interpretación de la norma constitucional fue elaborada por el máximo tribunal de la jurisdicción administrativa en la sentencia del Consejo de Estado, AC-11861 de 2001. Los hechos que originaron la decisión que contiene esta subregla jurisprudencial se originaron en demanda de pérdida de investidura promovida en contra del Representante a la Cámara Luis Javier Castaño Ochoa, por incumplir la causal contenida en el numeral 1 del artículo 179 de la Constitución Política. Lo anterior, en la medida en la que él había sido condenado por sentencia judicial de la Corte de Distrito de Estados Unidos para el Distrito Sur de la Florida a pena privativa de la libertad de 51 años de prisión, bajo el "Cargo 1 Conspiración para auxiliar y proteger la posesión y distribución de cocaína Título 18 USC 846 y 18 USC Sección 2 Cargo 2 Conspiración para defraudar y de esconder moneda de los Estados Unidos. Título 18, USC 371". El Consejo de Estado encontró plenamente acreditado que "la materialidad de las conductas por las que fue condenado el demandado por la justicia de los Estados Unidos no tenían el carácter de delitos políticos o culposos". Por este motivo, el alto tribunal decretó la pérdida de investidura del congresista con base en una sentencia emitida por juez extranjero.

18 Consejo de Estado, Sentencia AC-11861 de 2001. 
forma a todos los sujetos procesales que deben ser notificados, o si la providencia fue recurrida y se encuentra a la espera de la resolución del recurso, no puede hablarse de una condena definitiva, ni ejecutoriada. Sobre el particular señaló la Sala Plena del Consejo de Estado, en decisión del 4 de septiembre de 2001, que: "Únicamente las condenas proferidas en sentencias judiciales en forma definitiva tienen la calidad de antecedentes penales y contravencionales en todos los órdenes legales". ${ }^{19}$

Sin embargo, esta jurisprudencia no ha sido muy prolija en determinar cómo debe entenderse el concepto de delito político del que trata el numeral 1 del artículo 179 de la Constitución Política. Es por ello que la clarificación de este concepto requiere de una revisión de la manera como la Corte Constitucional y la legislación vigente han comprendido dicho concepto.

Inicialmente, la Corte Constitucional consideró la razonabilidad de la excepción a la inhabilidad política por condenas relacionadas con la comisión de delitos políticos, al entender que el delito político, claramente diferente del delito común, puede ser objeto de perdón y olvido, según las reglas aplicables para instituciones como la amnistía. Además, precisó que de no existir la posibilidad institucional de una reincorporación civil con todas las prerrogativas de acceso al ejercicio y control del poder político para quienes, al dejar la actividad subversiva, acogen los procedimientos democráticos con miras a la canalización de sus inquietudes, ideales y futuro desempeño de funciones públicas, los procesos de diálogo con grupos alzados en armas estarían llamados al fracaso. ${ }^{20}$

En la Sentencia C-928 del 2005, la Corte Constitucional a su vez definió el delito político como "aquella infracción penal cuya realización busca el cambio de las instituciones o sistemas de gobierno para implantar otros que el sujeto activo, generalmente caracterizado por su espiritu altruista y generoso, considere más justos". ${ }^{21}$ En esta decisión, para efectos de posibilitar la concesión de indultos, el alto tribunal consideró que era posible que se decretaran indultos por delitos de naturaleza no política o de naturaleza común a condición de que los delitos objeto del indulto tuvieran algún grado de conexidad con los delitos políticos. ${ }^{22}$

Pero la posibilidad de conceder indultos por delitos en conexidad con los delitos políticos no es ilimitada. Es preciso señalar que en virtud de lo preceptuado por las leyes 733 de 2002 y 1108 de 2006, la conexidad de los delitos políticos excluye los "actos atroces de ferocidad o barbarie, terrorismo, secuestro, genocidio, homicidio cometido fuera de combate o colocando a la víctima en estado de indefensión”. ${ }^{23}$

19 Colombia, Consejo de Estado, e2001-00098 de 2001.

20 Colombia, Corte Constitucional, Sentencia C-194 de 1995.

21 Ibid., Sentencia C-928 de 2005.

22 Idem.

23 La Convención Interamericana sobre Desaparición Forzada de Personas, aprobada por la Ley 707 de 2001, en su artículo quinto señala que el delito de desaparición forzada no será considerado político para efectos de extradición (Organización de los Estados Americanos, Convención Interamericana sobre Desaparición Forzada de Personas, art. 5. junio 9 de 1994). Además, la Convención 
Igualmente, la Ley 782 de 2002 y el artículo 13 de la Ley 733 de 2002 establecen la prohibición de conceder indultos o amnistías por este tipo de conductas. ${ }^{24}$

Sin embargo, ni estas normas jurídicas, ni las decisiones judiciales sobre esta materia han decantado el impacto que tiene la idea de la conexidad de los delitos políticos a efectos de las concesiones de indultos con la determinación de la inhabilidad política establecida en el numeral 1 del artículo 179 de la Constitución Política.

Por este motivo, no hay mayor claridad en nuestro contexto acerca del efecto de concesión de amnistias e indultos por delitos conexos con los delitos políticos frente al derecho de elegibilidad politica en el contexto colombiano.

Es deber de quien considere importante tener esta claridad acudir a la interpretación del término condena. Por ello, la renuncia a la persecución penal que implica la figura de la amnistía, aun si esta se concede por delitos de naturaleza conexa al delito político, habilita a los amnistiados para ser elegidos en el Congreso de la República. Lo anterior en la medida en que no existe, ni existirá nunca, la condena penal. Por el contrario el indulto, definido como "un mecanismo de extinción de la pena”, ${ }^{25}$ conlleva la existencia de la condena pero la liberación de su ejecución, lo que implicaría la conservación de la inhabilidad política en estos casos. Por último, quienes sean indultados por delitos políticos o culposos no se encuentran inhabilitados en la medida en que la limitación de la que se viene hablando, por expresa exclusión de la Constitución, no se hace extensible a estos supuestos.

\section{LAS MODIFICACIONES AL RÉGIMEN DE INHABILIDADES PARA SER ELEGIDO CONGRESISTA COMO CONSECUENCIA DEL PROCESO DE PAZ}

Teniendo en cuenta los distintos elementos que han caracterizado la limitación al derecho a ser elegido como consecuencia de la imposición de sanciones penales, es preciso analizar los cambios impuestos a esta limitación como consecuencia

Interamericana contra el Terrorismo, aprobada mediante la Ley 1108 de 2006, establece una lista de delitos que no se pueden considerar como políticos, para efectos de extradición o asistencia jurídica mutua (Organización de los Estados Americanos, Convención Interamericana contra el Terrorismo, arts. 2 y 11, junio 3 de 2002). Por su parte, la Corte Constitucional ha señalado que el delito de terrorismo no puede ser considerado como político.

24 Determina el artículo 50 de la Ley 782 de 2002: "El Gobierno Nacional podrá conceder, en cada caso particular, el beneficio de indulto a los nacionales que hubieren sido condenados mediante sentencia ejecutoriada, por hechos constitutivos de delito político cuando a su juicio, el grupo armado organizado al margen de la ley con el que se adelante un proceso de paz, del cual forme parte el solicitante, haya demostrado su voluntad de reincorporarse a la vida civil. También se podrá conceder dicho beneficio a los nacionales que, individualmente y por decisión voluntaria, abandonen sus actividades como miembros de los grupos armados organizados al margen de la ley y así lo soliciten, y hayan además demostrado, a criterio del Gobierno Nacional, su voluntad de

reincorporarse a la vida civil. No se aplicará lo dispuesto en este título a quienes realicen conductas constitutivas de actos atroces de ferocidad o barbarie, terrorismo, secuestro, genocidio, homicidio cometido fuera de combate o colocando a la víctima en estado de indefensión".

Colombia, Corte Constitucional, Sentencia C-695 de 2002. 
del Acuerdo de Paz suscrito entre el Gobierno de Colombia y el grupo insurgente FARC. En lo que sigue se identificarán estos cambios con mayor detenimiento.

\subsection{El contexto del proceso de paz}

Después de muchos intentos de resolver el conflicto armado interno entre las fuerzas del Estado colombiano y las FARC, el gobierno del presidente Juan Manuel Santos dio inicio, en el año 2011, a un proceso de negociación que se adelantó en La Habana (Cuba). Estas negociaciones se realizaron con la participación de delegados del Gobierno, de los altos miembros del grupo guerrillero y con la observación de la comunidad internacional. Los resultados de ese proceso de negociación fueron condensados en un documento de acuerdo final suscrito el 24 de noviembre de 2016 .

Este documento plasmó la reincorporación de los miembros de las FARC a la vida civil y la dejación de las armas del grupo insurgente, bajo el entendido de que era necesaria la realización de una serie de modificaciones estructurales a aspectos del sistema jurídico, político, económico y social del Estado colombiano. Estas modificaciones eran requeridas con el fin de facilitar la transición de este grupo armado a la vida democrática.

Uno de los puntos de este Acuerdo de Paz entre el Gobierno de Colombia y las FARC estableció que se permitiría la creación de espacios institucionales para la promoción de las ideas políticas defendidas por esta organización y sus miembros. Este compromiso se desarrolló en los acuerdos de paz a partir del impulso de un plan de modificaciones institucionales encaminadas a dar respuesta a dos interrogantes: i) cómo se iban a generar los espacios institucionales para la creación de los canales de difusión de las ideas políticas del grupo insurgente, y ii) quién iba a estar habilitado para representar estas ideas politicas en los nuevos espacios institucionales creados como consecuencia del proceso de paz.

\subsection{La promoción de las ideas políticas de la organización en proceso de transición como un acuerdo para compartir el poder en virtud del proceso de paz}

El acuerdo determinó una serie de condiciones para la creación de un nuevo partido político que defendiera la plataforma ideológica del grupo insurgente en transición a la legalidad. Los acuerdos señalaron la obligación para el Estado colombiano de otorgar la personería jurídica al partido político de la organización insurgente. ${ }^{26}$ Este reconocimiento, igualmente, iba acompañado de una prerrogativa en la que se habilitaba a dicho partido político para hacer parte del Congreso de Colombia.

26 En la Resolución 2691 de 2017, el Consejo Nacional Electoral reconoció la personería jurídica al partido político Fuerza Alternativa Revolucionaria del Común (FARC), se ordenó el registro de sus estatutos, la plataforma política, el código de ética, el logo-símbolo, e inscribió los nombres de las personas designadas para integrar sus órganos de dirección, gobierno y administración. 
Esta configuración, de conformidad con el Acuerdo de Paz, se daria a través dos vías: una directa y otra mediada por el proceso electoral.

Por este motivo, el Acuerdo de Paz estableció la asignación directa de 10 curules a los miembros del nuevo partido político denominado Fuerza Alternativa Revolucionaria del Común (FARC), sin que estos actores politicos tuvieran que competir por ellas. Esta prerrogativa se acordó para los procesos electorales de 2018 al 2022 y del 2022 al 2026. Asimismo, el Acuerdo de Paz permitió que el partido de la organización, una vez obtenida su personería política, inscribiera candidatos para competir por curules adicionales durante los procesos electorales mencionados y en procesos posteriores a estas fechas.

La creación de mecanismos de inclusión de las perspectivas políticas de los grupos en conflicto en los escenarios democráticos en sociedades que afrontan contextos de transición es una situación común. De esta manera, la literatura sobre la materia ha puesto de presente que:

A postwar society is a country that has suffered from intense and severe arm conflict. [...]. In this environment institutions building is often understood as the initial creation or reform of formal state institutions (e. g. constitutions, electoral [laws], property rights, the government system and the security sector) (Helmke and Levitsky, 2004; North, 1990) in a way that promotes nonviolent conflict management between social and political groups. "Desirable" outcomes are typically related to the prevention of the recurrence of war or armed conflict and may therefore include the implementation of democracy or equal representation of politically salient groups, especially in divide societies. ${ }^{27}$

Así, el corolario de las negociaciones de paz en contextos de conflicto armado interno implica la realización de reformas legales o constitucionales que faciliten la participación política de los miembros de los grupos en confrontación. Estos espacios han sido identificados por la literatura como escenarios de distribución, arreglos para compartir el poder o power sharing agreements. ${ }^{28}$

Dentro del conjunto de fórmulas que recogen este tipo de arreglos es posible identificar las siguientes: i) la creación de nuevos partidos políticos, ${ }^{29}$ ii) la ampliación de la base de electores para universalizar el sufragio, iii) la modificación de los sistemas electorales como fórmula para facilitar la entrada de los nuevos actores políticos al proceso democrático, ${ }^{30} \mathrm{o}$ (iv) la participación de miembros de los grupos en

27 Nadine Ansor y Sabine KurTerbach, Institutional reforms and peace building, New York, Routledge, 2017, p. 5.

28 La idea de power sharing como resultado de los procesos de paz ha sido definida en los siguientes términos: "Power-sharing means dividing the institutions of governance between political parties and rebel movements, in the context of a new constitution and democratic elections" (Patricia DALEY, "The Burundi peace negotiations: An african experience of peace-making”, Review of African

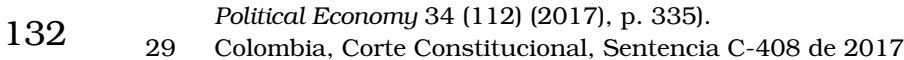

30 Ainara Малсево, "La transformación de los sistemas electorales: la reforma electoral durante la transición democrática en Sudáfrica”, Revista Latinoamericana de Politica Comparada 11 (2016). 
conflicto en las instituciones estatales, especialmente, en los órganos de la rama ejecutiva, entre otros.

Tal y como se observó, en el proceso de paz de Colombia, los arreglos para compartir el poder se centraron en la creación del nuevo partido político, Fuerza Alternativa Revolucionaria del Común (FARC) para permitir a los excombatientes convertirse en miembros del Congreso. Sin embargo, es necesario precisar con algún detalle, no solamente cómo se desarrollaron estos acuerdos, sino también quiénes van a ser los beneficiarios directos de los mismos.

\section{3. ¿A quién se habilita para conformar los nuevos escenarios, creados en virtud del Acuerdo de Paz, para compartir el poder?}

La literatura existente sobre los arreglos políticos en contextos de transición, además de no ser tan extensa, solamente ha observado las lineas más gruesas de este tipo de arreglos. Estas líneas gruesas, generalmente, son analizables a partir del examen de los contenidos de ciertas cláusulas que contienen esta clase de arreglos, las cuales se encuentran presentes en los acuerdos de paz con cierto nivel de frecuencia. ${ }^{31}$ Sin embargo, para su desarrollo posterior, estas cláusulas requieren de normas de rango legal o constitucional que en muchos casos no son reseñadas en las obras que analizan este campo de investigación, ni capturadas por la literatura sobre el tema.

En otros términos, esta literatura identifica y analiza, especialmente, cómo se generan estos acuerdos mediante la descripción de los cambios en los sistemas electorales o la inclusión de nuevos actores políticos que emergen tras los procesos de paz. Sin embargo, estos análisis no dan muchos detalles o respuestas frente a interrogantes del tipo ¿quién va a compartir el poder con quién, en los contextos de transición? ${ }^{32}$

No obstante, subrayar las respuestas a estos interrogantes resulta un asunto cada vez más relevante por diversas razones. La primera está relacionada con la determinante influencia de los actores internacionales en la construcción de paz a través de acuerdos o procesos de negociación.

La segunda razón está directamente conectada con la importancia de la idea de los derechos humanos como exigencias que imponen limites reales a las sociedades actuales, aun en contextos de conflicto armado. La reconciliación del ideal de protección de los derechos humanos con la obtención de la paz puede resultar

31 Sobre el particular se puede observar la matriz comparativa del Instituto Kroc sobre acuerdos de paz en el mundo. Este instituto establece lo relativo a los acuerdos para compartir el poder como uno de los criterios de indización de la información sobre los diversos acuerdos de paz suscritos en el mundo. Esta matriz se encuentra disponible en https://peaceaccords.nd.edu/peace-accords.

32 Andreas MeHLER, "Peace and power sharing in Africa: a not so obvious relationship", African Affairs 108 (2009), p. 453. 
sumamente dificil en algunas circunstancias. Esta dificultad se acrecienta, especialmente, en aquellos contextos en los que la respuesta a los interrogantes acerca de quién ocupará las posiciones políticas generadas como consecuencia de los mecanismos para compartir creados en los acuerdos de paz se traslape con la identidad de perpetradores de crimenes de lesa humanidad. Si esta superposición otorga a los perpetradores de estas conductas la representación política, el acto de hacer presencia otra vez en los escenarios representativos, ${ }^{33} \mathrm{o}$ en los órganos de gobierno como resultado del proceso puede llegar a generar serias tensiones frente a las víctimas de este tipo de crímenes.

Autores como Leka, Martin y Herman han puesto de presente las tensiones existentes entre las cláusulas para distribuir el poder político en los acuerdos de paz y la protección de los derechos humanos al señalar:

For example, peace negotiations and peace processes deal with the disarmament, demobilization, and reintegration of ex-combatants to guarantee that they do not return fighting. This may require a host of guarantees to parties that may be at cross-purposes with human rights protections, including amnesty but also other concessions to individuals or groups who may be responsible for grave violations of human rights or international humanitarian law. Thus the 1999 Lomé Agreement in Sierra Leone granted a blanket amnesty, and guaranteed notorious rebel leader Foday Sankoh a position in government. ${ }^{34}$

Por su parte, Mehler hizo una relación precisa de algunas de las fórmulas que fueron diseñadas en los países africanos que suscribieron procesos de paz desde 1999 hasta 2008. De conformidad con sus hallazgos, el acuerdo de Lome, suscrito en el año de 1999, permitió que el líder del Frente Revolucionario Unido (RUF), Foday Sankoh, se convirtiera en vice-presidente de Sierra Leona. Este acuerdo, igualmente, distribuyó cuatro ministerios a este grupo armado. ${ }^{35}$ En efecto, el Acuerdo de Lome determina que:

Chairmanship of the Board of the Commission for the Management of Strategic Resources, National Reconstruction and Development (CMRRD) as provided for in Article VII of the present Agreement shall be offered to the leader of the RUF/SL, Corporal Foday Sankoh. For this purpose, he shall enjoy the status of Vice President and shall therefore be answerable only to the President of Sierra Leone. ${ }^{36}$

Los acuerdos firmados en el Congo el 19 de abril de 2002, para terminar el conflicto armado de esa nación, permitieron que Jean Pierre Bemba, líder del Movimiento de Liberación del Congo (MLC) ostentara el cargo de primer ministro del país africano en la etapa de transición del proceso de paz. ${ }^{37}$

33 Ana Pitkin, The Concept of Representation, Berkeley, University of California Press, 1992.

34 Chandra Lecka, Olga Martin y Johana Herman, War, Conflict and Human Rights, New York, Routled-

134 ge, 2016, p. 29.

35 Mehler, "Peace and power sharing in Africa: a not so obvious relationship", ob. cit., p. 460.

36 Acuerdo de Lome, 1999, art. 5.2.

37 Mehler, "Peace and power sharing in Africa: a not so obvious relationship", ob. cit., p. 460. 
Por último, el Acuerdo de Paz de Ouagadougou, suscrito el 4 de marzo de 2007, para dar terminación al conflicto armado de Costa de Marfil, estableció que el líder de la fracción rebelde, Guillaume Soro, se convertiría en primer ministro del país, lo cual no fue reconocido directamente en el acuerdo sino en un decreto separado. ${ }^{38}$

En el contexto latinoamericano también es posible identificar algunas fórmulas para la distribución del poder como mecanismos de transición hacia la paz. Sin embargo, estas formulaciones son demasiado amplias como para concluir si en ellas existió o no alguna superposición entre beneficiarios de los arreglos para compartir el poder y perpetuadores de crimenes de lesa humanidad. El Acuerdo de Chapultepec, suscrito el 16 de junio de 1991 para finalizar el conflicto armado en El Salvador, previó el reconocimiento del Frente Farabundo Martí para la Liberación Nacional (FMLN) como un partido político con posibilidad de competir, a partir de la suscripción del Acuerdo, en los procesos electorales de ese país. Igualmente, este acuerdo determinó la: "Adopción de las medidas legislativas o de otro carácter que fueren necesarias para garantizar a los excombatientes del FMLN el pleno ejercicio de sus derechos civiles y políticos, en orden a su reincorporación, dentro de un marco de plena legalidad, a la vida civil, politica e institucional del país". ${ }^{39}$

En el contexto colombiano se establecieron una serie de compromisos muy complejos para determinar quiénes iban a ser los beneficiarios de los mecanismos acordados en el proceso de paz para compartir el poder. La complejidad de estos arreglos está dada por la imbricación de los acuerdos para compartir el poder con los acuerdos sobre justicia transicional establecidos en la negociación entre las partes. De esta manera, el Acuerdo de Paz de La Habana estableció que los miembros de las FARC podrían participar en los mecanismos de distribución del poder creados como consecuencia del proceso de paz, sin importar la naturaleza de los delitos cometidos por los excombatientes.

Para este fin, el Acuerdo de Paz señaló que una vez se sometieran a la justicia transicional diseñada en la negociación, los excombatientes recobrarian la habilitación para ser elegidos. Sobre el particular, en el Acuerdo de Paz se señaló: "La imposición de cualquier sanción en el Sistema Integral de Verdad, Justicia, Reparación y No Repetición no inhabilitará para la participación política ni limitará el ejercicio de ningún derecho, activo o pasivo, de participación política, para lo cual las partes acordarán las reformas constitucionales pertinentes". ${ }^{40}$

Esta cláusula del Acuerdo de Paz fue, a su vez, recogida en el Acto Legislativo 01 de 2017 que desarrolla lo relacionado con el tema de justicia transicional en el Acuerdo de Paz. Esta norma de rango constitucional crea el Sistema Integral de Verdad, Justicia y Reparación, determina los órganos y la competencia para investigar los crímenes ocurridos con ocasión del conflicto y establece la naturaleza de las sanciones dentro del sistema, entre otras cuestiones relevantes.

\footnotetext{
38 Ibid., p. 459.

39 Acuerdo de Chapultepec, 1991, capítulo 5.1.

40 Acuerdo Final, 2016, p. 150.
} 
En dicho acto legislativo se recoge integralmente la disposición plasmada en el Acuerdo de Paz en los siguientes términos:

Art. 20: La imposición de cualquier sanción en la JEP no inhabilitará para la participación política ni limitará el ejercicio de ningún derecho, activo o pasivo, de participación política. Parágrafo. Respecto a aquellas personas que pertenezcan a organizaciones rebeldes que hayan firmado un acuerdo de paz con el Gobierno, a efectos de reincorporación, quedarán en efecto suspensivo las condenas derivadas de delitos competencia del Tribunal para la Paz impuestas por la justicia ordinaria o disciplinaria, hasta que estas condenas hayan sido tratadas por la Jurisdicción Especial para la Paz para lo de su competencia. ${ }^{41}$

No obstante, es preciso señalar que este tipo de acuerdos para compartir el poder no son del todo conciliables con la garantía y protección del derecho internacional humanitario. En efecto, se puede evidenciar que algunos de los beneficiarios de los acuerdos para compartir el poder que fueron creados en el contexto africano están empezando a ser procesados en la Corte Penal Internacional por la comisión de crímenes de lesa humanidad. ${ }^{42}$

Para el caso colombiano, como anota Andrés Molano, el estudio de los desafios que tendrá que encarar la justicia para el posconflicto implica la atención de dos asuntos diferentes, pero estrechamente vinculados: "la justicia del posconflicto" y "la justicia en el posconflicto". La primera se refiere a la justicia transicional, mientras que la segunda tiene que ver con la justicia ordinaria, las cuales coexistirán durante el posconflicto. Dicha coexistencia no es sencilla y estará atravesada por contradicciones, cuellos de botella y demás problemáticas que se enmarcan dentro de lo que este autor denomina "gobernabilidad del posconflicto". ${ }^{4}$

Precisamente, la "gobernabilidad del posconflicto" es el aspecto general que subyace al estudio de cualquier institución jurídica ordinaria en el marco del Acuerdo de $\mathrm{Paz}$ colombiano, entre ellas, el régimen de inhabilidades y sus transformaciones a partir de la aplicación de la justicia transicional.

41 Acto Legislativo 01 de 2017.

42 En efecto, el más notorio de estos casos es la decisión proferida por la Corte Penal Internacional (CPI), Judgment ICC-01-05-01-08 de 2016. En este fallo de instancia, del 21 de junio de 2016, este Tribunal encontró culpable a Jean Pierre Bemba, beneficiario de los acuerdos para compartir el poder en el Congo, por crimenes de lesa humanidad y crimenes de guerra cometidos por los milicianos del Movimiento para la Liberación del Congo (MLC), en contra de la población del Congo. Aunque de acuerdo con la decisión del tribunal internacional, los crímenes objeto de la decisión fueron cometidos de forma posterior a los Acuerdos de Lusaka y de Sun City del año 2002, la Corte desestimó como argumento de la defensa del acusado la contribución de Bemba al proceso de pacificación de su país. Lo anterior, al no haber encontrado una prueba de la real naturaleza de esta contribución. Por su parte, el presidente de Costa de Marfil, Laurent Gbagbo, quien en el acuerdo de Ouagadougou continuó ostentando esta posición como mecanismo de distribución del poder a partir de este Acuerdo de Paz, en la actualidad se encuentra en la etapa de antejuicio por crímenes de lesa humanidad, perpetuados después de la suscripción de los Acuerdos de 2007, de conformidad con la decisión de la CPI (Case ICC-02/11-01/11-656 de 2014).

43 Andrés Molano RoJas, "Justicia para el posconflicto: viejos y nuevos problemas en escenarios complejos”, en Andrés Molano RoJas (ed.), El posconflicto en Colombia. Reflexiones y propuestas para recorrer la transición, Bogotá, Instituto de Ciencia Política Hernán Echavarría Ológaza y Fundación Konrad Adenauer en Colombia (KAS), 2015, p. 17. 
A la importancia de este tema también contribuye la perspectiva de la "cultura de la justicia” que impera en Colombia, entendida esta como el imaginario socialmente compartido sobre la noción de justicia (en abstracto) así como sobre la administración de justicia (estructura orgánica a cargo de su cumplimiento). En el país, pese a las importantes transformaciones institucionales ocurridas en los últimos años, la noción de justicia parece seguir dominada por una concepción instrumental de esta, en la que el revanchismo prima sobre la satisfacción efectiva y el arbitraje racional de los derechos. ${ }^{44}$

El paradigma de la justicia transicional debería poder incluirse en la noción de justicia a fin de facilitar un distanciamiento del imaginario social desde el revanchismo hacia la idea del arbitraje racional de los derechos. Sin embargo, la idea de justicia como arbitraje, en todo caso, debe comprender la real dimensión de los cambios institucionales que se plantean en virtud de los acuerdos para compartir el poder creados como consecuencia del proceso de paz. Lo anterior, con el fin de evaluar el nivel de racionalidad de estos acuerdos. En lo que se sigue, el texto se centrará en ese propósito.

\section{El Acuerdo de paz y los escenarios de ESTABILIDAD Y DE CAMBIO DE LA INHABILIDAD POLÍTICA POR CONDENA PENAL}

En seguimiento de estos precedentes, y con el propósito de dar cumplimiento a los acuerdos de paz, el Congreso de la República expidió la Ley 1820 de 30 de diciembre de 2016, y el Acto Legislativo 01 de 2017. Estas disposiciones, a partir de su promulgación, deben ser tenidas en cuenta para la imposición de restricciones al derecho a ser elegido, de conformidad con lo establecido en el numeral 1 del artículo 179 de la Constitución Política.

La conjugación de estas normas permite dilucidar con mayor claridad quiénes van contar con facultades para beneficiarse de los acuerdos para compartir el poder que se crearon con ocasión del proceso de paz. Frente a este tema se puede señalar que estas disposiciones dejaron estables ciertas cuestiones relativas a la mencionada inhabilidad pero, a su vez, cambiaron otras.

Lo que no cambia frente a la norma sobre inhabilidades en Colombia es que las personas pertenecientes a las FARC que fueron procesadas o condenadas por delitos políticos ${ }^{45}$ o por delitos culposos van a contar con la misma posibilidad que cualquier otro ciudadano colombiano de postularse los cargos de representación política. En suma, estos excombatientes se encuentran en plena capacidad de ocupar los escenarios para compartir el poder que se crearon con ocasión del proceso de paz.

44 Ibid., p. 18.

45 Estos delitos, según la ley, son: rebelión, sedición, asonada, conspiración y seducción, usurpación y retención ilegal de mando y los delitos conexos con estos, de conformidad con esta ley, a quienes hayan incurrido en ellos (Ley 1820 de 2016). 
No obstante, el análisis conjunto de la Ley 1820 de 2016 y del Acto Legislativo 01 de 2017 permite señalar que el Acuerdo de Paz generó modificaciones importantes a la inhabilidad contenida en el numeral 1 del artículo 179 de la Constitución Política.

De la lectura de estas disposiciones se sigue que los miembros de las FARC que antes del proceso de paz recibieron condenas por la comisión de delitos conexos con los delitos políticos establecidos en la Ley 1820 de $2016,{ }^{46}$ pero que hayan sido o vayan a ser objeto de indultos no podrán postularse a los cargos de representación popular en el Congreso de la República. Lo anterior, en virtud de que la inhabilidad establecida en el numeral 1 del artículo 179 de la Constitución Política excluye del principio de elegibilidad política de forma permanente a quienes hayan sido condenado por delitos de naturaleza distinta a los delitos políticos o culposos.

Por su parte, el Acto Legislativo 01 de 2017 determinó que la Jurisdicción Especial para la Paz (JEP), a través de la Sala de Amnistía e Indulto, puede conceder amnistías por la comisión de delitos con ocasión del conflicto. Sin embargo, la renuncia de la persecución penal (en el caso de la amnistía) o el perdón de la ejecución de la sanción penal mediante el indulto no generan ningún tipo de limitación a la elegibilidad política en virtud de lo ordenado por el parágrafo 20 del Acto Legislativo en cuestión.

Este Acto Legislativo había establecido, asimismo, que las sanciones impuestas por el Tribunal para la Paz no iban a generar ningún tipo de limitación de los derechos a la elegibilidad politica de los excombatientes. Lo anterior, sin importar la naturaleza o gravedad de la conducta penal, ni su grado de afectación del DIH.

La tabla 2 sintetiza la relación existente entre los tratamientos penales como consecuencia del proceso de paz y la elegibilidad politica, de conformidad con lo dispuesto originalmente por este marco normativo.

46 Los delitos conexos de conformidad con esta ley son: apoderamiento de aeronaves, naves o medios de transporte colectivo cuando no hay concurso con secuestro; constreñimiento para delinquir; violación de habitación ajena; violación ilícita de comunicaciones; ofrecimiento, venta o compra de instrumento apto para interceptar la comunicación privada entre personas; violación ilícita de comunicaciones o correspondencia de carácter oficial; utilización ilícita de redes de comunicaciones; violación de la libertad de trabajo; injuria; calumnia; injuria y calumnia indirectas; daño en bien ajeno; falsedad personal; falsedad material de particular en documento público; obtención de documento público falso; concierto para delinquir; utilización ilegal de uniformes e insignias; amenazas; instigación a delinquir; incendios; perturbación en servicio de transporte público colectivo $\mathrm{u}$ oficial; tenencia y fabricación de sustancias u objetos peligrosos; fabricación, porte o tenencia de armas de fuego, accesorios, partes o municiones; fabricación, porte o tenencia de armas, municiones de uso restringido, de uso privativo de las fuerzas armadas o explosivos; perturbación de certamen democrático; constreñimiento al sufragante; fraude al sufragante; fraude en inscripción de cédulas; corrupción al sufragante; voto fraudulento; contrato sin cumplimiento de requisitos legales; violencia contra servidor público; fuga; espionaje (art. 16, Ley 1820 de 2016). Incluso, la Sala de Amnistía e Indulto de la Jurisdicción Especial para la Paz (JEP) tiene la facultad legal de considerar otros delitos políticos conexos, distintos de los enunciados en el artículo 16, con base en los criterios fijados en el artículo 23 de la ley en cita (art. 23, Ley 1820 de 2016). 


\section{Tabla 2. Relación entre la elegibilidad política y el tratamiento penal}

\begin{tabular}{|c|c|c|c|c|}
\hline $\begin{array}{c}\text { Tipo de tratamiento } \\
\text { penal }\end{array}$ & $\begin{array}{l}\text { Autoridad } \\
\text { responsable }\end{array}$ & Nivel de afectación del DIH & $\begin{array}{l}\text { Inhabilidad } \\
\text { para ser elegido } \\
\text { en calidad de } \\
\text { representante }\end{array}$ & $\begin{array}{l}\text { Duración de } \\
\text { la inhabilidad }\end{array}$ \\
\hline $\begin{array}{l}\text { Condenados por de- } \\
\text { litos con conexidad a } \\
\text { los delitos politicos y } \\
\text { por delitos comunes }\end{array}$ & Justicia ordinaria & Indeterminable & Si & Perpetua \\
\hline $\begin{array}{l}\text { Indulto por la comi- } \\
\text { sión de delitos conexos } \\
\text { con los delitos politicos }\end{array}$ & $\begin{array}{l}\text { Presidente de la } \\
\text { República }\end{array}$ & $\begin{array}{l}\text { Bajo: delitos conexos con los } \\
\text { delitos politicos en los es- } \\
\text { trictos términos establecidos } \\
\text { en el art. } 16 \text { de la Ley } 1820 \\
\text { de } 2016\end{array}$ & Sí & Perpetua \\
\hline $\begin{array}{c}\text { Amnistía de delitos } \\
\text { conexos con los delitos } \\
\text { políticos }\end{array}$ & $\begin{array}{c}\text { Sala de Amnis- } \\
\text { tias e Indulto de } \\
\text { la JEP }\end{array}$ & $\begin{array}{l}\text { Medio: delitos conexos con } \\
\text { los delitos políticos en los es- } \\
\text { trictos términos establecidos } \\
\text { en el art. } 16 \text { de la Ley } 1820 \\
\text { de } 2016\end{array}$ & No & $\begin{array}{c}\text { No existe } \\
\text { inhabilidad }\end{array}$ \\
\hline $\begin{array}{c}\text { Amnistía o indulto de } \\
\text { los delitos conexos con } \\
\text { los delitos políticos no } \\
\text { expresamente consa- } \\
\text { grados en el art. } 16 \text { de } \\
\text { la Ley } 1820 \text { de } 2016 \text {, } \\
\text { pero que puedan ser } \\
\text { considerados como } \\
\text { conexos por la Sala de } \\
\text { Amnistias e Indultos } \\
\text { de la JEP }\end{array}$ & $\begin{array}{c}\text { Sala de Amnistías } \\
\text { e Indulto de la } \\
\text { JEP }\end{array}$ & $\begin{array}{l}\text { Alto: delitos conexos con los } \\
\text { delitos políticos: i) las muer- } \\
\text { tes en combate compatibles } \\
\text { con el derecho internacional } \\
\text { humanitario, y la aprehen- } \\
\text { sión de combatientes efectua- } \\
\text { da en operaciones militares, } \\
\text { ii) delitos en los que el sujeto } \\
\text { pasivo es el Estado, y iii) las } \\
\text { conductas dirigidas a facili- } \\
\text { tar, apoyar, financiar u ocul- } \\
\text { tar el desarrollo de la rebelión } \\
\text { (art. 23, Ley 1820 de 2016) }\end{array}$ & No & $\begin{array}{l}\text { No existe } \\
\text { inhabilidad }\end{array}$ \\
\hline $\begin{array}{c}\text { Delitos que no puedan } \\
\text { ser objeto de amnistía } \\
\text { e indulto }\end{array}$ & $\begin{array}{l}\text { Sala de Reco- } \\
\text { nocimiento de } \\
\text { Verdad y Respon- } \\
\text { sabilidad, Sala de } \\
\text { Ausencia de Re- } \\
\text { conocimiento de } \\
\text { Verdad y Respon- } \\
\text { sabilidad y Sala } \\
\text { de Apelaciones del } \\
\text { Tribunal para la } \\
\text { Paz de la Juris- } \\
\text { dicción Especial } \\
\text { para la Paz-JEP. }\end{array}$ & $\begin{array}{l}\text { Altísimo: delitos de lesa hu- } \\
\text { manidad, el genocidio, los } \\
\text { graves crimenes de guerra, la } \\
\text { toma de rehenes u otra pri- } \\
\text { vación grave de la libertad, } \\
\text { la tortura, las ejecuciones } \\
\text { extrajudiciales, la desapari- } \\
\text { ción forzada, el acceso carnal } \\
\text { violento y otras formas de } \\
\text { violencia sexual, la sustrac- } \\
\text { ción de menores, el desplaza- } \\
\text { miento forzado, además del } \\
\text { reclutamiento de menores }\end{array}$ & No & $\begin{array}{l}\text { No existe } \\
\text { inhabilidad }\end{array}$ \\
\hline
\end{tabular}

Fuente: elaboración propia con base en el artículo 179 de la Constitución Política, el Acto Legislativo 01 de 2017 y la Ley 1820 de 2016.

El Acuerdo de Paz y las normas que lo desarrollaron establecieron la imposibilidad de amnistiar o indultar delitos o crimenes contra la humanidad, pero no determinaron ningún tipo de condicionamiento al derecho a la habilitación política de estos excombatientes. En este orden de ideas, este acuerdo contempló una total superposición de la elegibilidad política con la realización de graves crimenes contra la humanidad. 


\subsection{El papel de la Corte Constitucional para morigerar el alcance de las modificaciones del Acuerdo de Paz en materia de elegibilidad política}

Es preciso señalar que la Corte Constitucional, en decisión reciente que aún no ha sido objeto de publicación, moderó los alcances del Acto Legislativo 01 de 2017 en relación con la elegibilidad política. A partir de esta moderación se considera que solo en la medida en que se otorgue plena verdad a las víctimas en los procesos adelantados ante la JEP, será posible disfrutar del derecho a la elegibilidad política. ${ }^{47}$

A partir de esta decisión del tribunal constitucional, la inhabilidad establecida en el numeral 1 del artículo 179 de la Constitución Política frente a los excombatientes tiene consecuencias distintas según el grado de verdad y de responsabilidad asumido por estos actores.

Así, esta inhabilidad continúa constituyéndose en una barrera que limita el derecho al sufragio activo de los excombatientes de las FARC en el caso en el que aquellos sean sancionados por la sección de Ausencia de Reconocimiento y Verdad y la Sección de Apelaciones del Tribunal para la Paz de la JEP, por incumplir con sus compromisos y aportes a la verdad y reparación de las víctimas. Pero, por el contrario, los excombatientes que sean sancionados por la sección de Reconocimiento de Verdad y Responsabilidad de la JEP podrán gozar a plenitud de sus derechos de elegibilidad politica sin importar la naturaleza de los delitos cometidos. Lo anterior como consecuencia del pleno reconocimiento de la verdad a las víctimas.

A pesar de que la decisión de la Corte morigera los efectos del marco legal originalmente creado a partir de los acuerdos, es necesario señalar que esta decisión no resulta del todo garantista en la protección del DIH. Lo anterior debido a que solo hasta que la JEP entre plenamente en funcionamiento, adelante los procesos y desarrolle los mecanismos para determinar los casos en los que existe o no pleno reconocimiento de la verdad, se podrá materializar lo ordenado por la Corte Constitucional.

En otros términos, como los arreglos para compartir el poder establecidos en el proceso de paz implican la posibilidad de que desde el 2018 se haga uso de los beneficios establecidos para compartir el poder, y dado que los procesos y procedimientos, así como el adelantamiento de las causas por parte de la JEP aún no tienen una fecha ni cierta, ni determinable, no queda claro cómo se puede conciliar

47 "Teniendo en cuenta los límites competenciales del Congreso en materia de implementación del Acuerdo Final mediante el procedimiento legislativo especial para la Paz, la Corte concluye que: i) resulta inexequible, a la luz del deber del Estado de investigar, juzgar y sancionar los crimenes más graves y de los principios de condicionalidad y finalidad, la aplicación del inciso primero del artículo transitorio 20 a los sancionados que no contribuyan a la consecución de los objetivos del Sistema Integral de Verdad, Justicia, Reparación y No Repetición, mediante el reconocimiento de verdad ple-

140 na sobre lo ocurrido y de responsabilidad por su participación en graves violaciones de los derechos humanos y graves infracciones al Derecho Internacional Humanitario, razón por la cual quienes sean objeto de las sanciones ordinarias a que se refiere el Acuerdo no serán beneficiarios de la regla sobre inhabilidades del inciso primero" (Corte Constitucional, Comunicado 55 de 2017, p. 22). 
esta decisión judicial y ofrecer plena garantía al DIH en los términos establecidos por la jurisprudencia de la Corte.

\section{AlgunOS PROBLEMAS JURÍdicos e interPRETATIVOS DEL CAMBIO DE LA INHABILIDAD POLÍTICA POR CONDENA PENAL A PARTIR DEL PROCESO DE PAZ}

Además de los problemas de efectividad de la decisión de la Corte Constitucional que mesuró el alcance original de los Acuerdos en relación con el tema de elegibilidad política, lo acordado en virtud del proceso de paz presenta un problema interpretativo adicional, conectado con el trato desigual que tal modificación empezaría a generar frente a otros ciudadanos colombianos. También frente a los propios excombatientes de las FARC que por haber sido objeto de condenas penales cumplidas o de indultos por la realización de delitos no lesivos del DIH no van a ver reestablecidos sus derechos al sufragio activo nunca y bajo ninguna circunstancia.

En este sentido, mientras que para estos ciudadanos la restricción de sus derechos politicos es insalvable y perpetua, para los excombatientes o ciudadanos que voluntariamente se sometan a los mecanismos de justicia transicional creados en el proceso de paz, estas restricciones pueden llegar a ser inexistentes. Lo anterior, sin importar que estos ciudadanos o excombatientes hubieran cometido conductas contrarias al DIH.

De acuerdo con esto, lo acordado conlleva una paradoja que puede formularse en los siguientes términos: entre menor grado de afectación del DIH tengan las conductas de los excombatientes -lo que explicaría el otorgamiento de la figura del indulto-, mayores y más amplias serán las restricciones para participar en calidad de elegidos en los mecanismos para compartir el poder creados con ocasión del proceso de paz. Por su parte, entre mayor grado de afectación del DIH tengan las conductas de los excombatientes, o de otros actores que se sometan voluntariamente a los mecanismos de justicia transicional, menores serán sus limitaciones para participar en calidad de elegidos en los mecanismos para compartir el poder creados como consecuencia del acuerdo.

Por este motivo, y para evitar los problemas que se originan por esta situación, y las afectaciones al derecho a la igualdad a la participación politica de los ciudadanos colombianos y de los propios excombatientes del grupo insurgente, se precisa de una modificación de la mencionada inhabilidad política que implique la existencia de inhabilidad politica por condenas penales, pero únicamente durante el término que dure dicha medida sancionatoria. Esta propuesta para comprender la inhabilitación política por condenas penales no resulta extraña. En efecto, múltiples sistemas constitucionales incorporan inhabilidades de naturaleza similar, pero ponen un limite temporal a este tipo de restricciones a la elegibilidad politica. La tabla 3 recoge las formulaciones de este tipo específico de inhabilidad en otros ordenamientos constitucionales. 
Tabla 3. Limitaciones a la elegibilidad política por condenas penales

\begin{tabular}{|c|c|}
\hline País & Inhabilidad electoral \\
\hline España & $\begin{array}{l}\text { Artículo } 6 . \\
\text { [...] 2. Son inelegibles: } \\
\text { a) Los condenados por sentencia firme, a pena privativa de libertad, en el periodo que dure la pena. } \\
\text { b) Los condenados por sentencia, aunque no sea firme, por delitos de rebelión, de terrorismo, contra } \\
\text { la Administración Pública o contra las Instituciones del Estado cuando la misma haya establecido la } \\
\text { pena de inhabilitación para el ejercicio del derecho de sufragio pasivo o la de inhabilitación absoluta o } \\
\text { especial o de suspensión para empleo o cargo público en los términos previstos en la legislación penal. }\end{array}$ \\
\hline Venezuela & $\begin{array}{l}\text { Artículo } 65 \text {. } \\
\text { No podrán optar a cargo alguno de elección popular quienes hayan sido condenados o condenadas } \\
\text { por delitos cometidos durante el ejercicio de sus funciones y otros que afecten el patrimonio públi- } \\
\text { co, dentro del tiempo que fije la ley, a partir del cumplimiento de la condena y de acuerdo con la } \\
\text { gravedad del delito. }\end{array}$ \\
\hline Bolivia & $\begin{array}{l}\text { Artículo } 28 \text {. } \\
\text { El ejercicio de los derechos políticos se suspende en los siguientes casos, previa sentencia ejecutoriada } \\
\text { mientras la pena no haya sido cumplida: } 1 \text {. Por tomar armas y prestar servicio en fuerzas armadas } \\
\text { enemigas en tiempos de guerra. } 2 \text {. Por defraudación de recursos públicos. } 3 \text {. Por traición a la patria. }\end{array}$ \\
\hline Uruguay & $\begin{array}{l}\text { Artículo } 80 . \\
\text { La ciudadania se suspende: } \\
\text { [...] 4. Por sentencia que imponga pena de destierro, prisión, penitenciaria o inhabilitación para el } \\
\text { ejercicio de derechos políticos durante el tiempo de la condena. }\end{array}$ \\
\hline Paraguay & $\begin{array}{l}\text { Artículo 197. De las inhabilidades } \\
\text { No pueden ser candidatos a senadores ni a diputados: } \\
\text { 1. los condenados por sentencia firme a penas privativas de libertas, mientras dure la condena; } \\
\text { 2. los condenados a penas de inhabilitación para el ejercicio de la función pública, mientras dure aquella; } \\
\text { 3. los condenados por la comisión de delitos electorales, por el tiempo que dure la condena. }\end{array}$ \\
\hline Argentina & $\begin{array}{l}\text { Artículo 3. Quiénes están excluidos. } \\
\text { Están excluidos del padrón electoral: } \\
\text { e) Los condenados por delitos dolosos a pena privativa de la libertad, y por sentencia ejecutoriada, } \\
\text { por el término de la condena. }\end{array}$ \\
\hline Perú & $\begin{array}{l}\text { Suspensión del ejercicio de la ciudadanía } \\
\text { Artículo } 10 \text {. El ejercicio de la ciudadanía y, por ende, el derecho a elegir y ser elegido se suspenden } \\
\text { en los casos siguientes: a) por resolución judicial de interdicción; b) por sentencia con pena privativa } \\
\text { de la libertad; c) por sentencia con inhabilitación de los derechos políticos. }\end{array}$ \\
\hline Chile & $\begin{array}{l}\text { Limitaciones por culpabilidad por delitos terroristas: } \\
\text { Artículo } 9 \text {. Incisos } 1 \text { y } 2 \text {. } \\
\text { El terrorismo, en cualquiera de sus formas, es por esencia contrario a los derechos humanos. } \\
\text { Una ley de quórum calificado determinará las conductas terroristas y su penalidad. Los responsables } \\
\text { de estos delitos quedarán inhabilitados por el plazo de quince años para ejercer funciones o cargos } \\
\text { públicos, sean o no de elección popular, o de rector o director de establecimiento de educación, o } \\
\text { para ejercer en ellos funciones de enseñanza; para explotar un medio de comunicación social o ser } \\
\text { director o administrador del mismo, o para desempeñar en él funciones relacionadas con la emisión } \\
\text { o difusión de opiniones o informaciones; ni podrán ser dirigentes de organizaciones políticas o re- } \\
\text { lacionadas con la educación o de carácter vecinal, profesional, empresarial, sindical, estudiantil o } \\
\text { gremial en general, durante dicho plazo. Lo anterior se entiende sin perjuicio de otras inhabilidades } \\
\text { o de las que por mayor tiempo establezca la ley. }\end{array}$ \\
\hline Ecuador & $\begin{array}{l}\text { Artículo } 64 . \\
\text { El goce de los derechos politicos se suspenderá, además de los casos que determine la ley, por las } \\
\text { razones siguientes: } 1 \text {. Interdicción judicial, mientras esta subsista, salvo en caso de insolvencia o } \\
\text { quiebra que no haya sido declarada fraudulenta. 2. Sentencia ejecutoriada que condene a pena pri- } \\
\text { vativa de libertad, mientras esta subsista. } \\
\text { Artículo } 14 \text {. } \\
\text { El goce de los derechos politicos o de participación se suspenderá, por las razones siguientes: } 1 . \\
\text { Interdicción judicial, mientras esta subsista, salvo en caso de insolvencia o quiebra que no haya } \\
\text { sido declarada fraudulenta. } 2 \text {. Sentencia ejecutoriada que sancione con pena privativa de libertad, } \\
\text { mientras esta subsista. } 3 \text {. Cuando el Tribunal Contencioso Electoral haya declarado en sentencia } \\
\text { ejecutoriada la responsabilidad por el cometimiento de alguna infracción de las tipificadas en esta } \\
\text { ley con esa sanción. }\end{array}$ \\
\hline
\end{tabular}

Fuente: elaboración propia con base en los textos de las constituciones citadas. 
Tal y como se muestra, la inhabilidad por condenas penales es común en los ordenamientos constitucionales contemporáneos, pero también es generalizada la determinación de un término finito en este tipo de formulaciones, el cual oscila entre la duración de la condena penal o un máximo de 15 años.

Esta modificación podría, a su vez, evitar que se produzcan superposiciones delicadas entre el reconocimiento de la habilitación política y la comisión de crímenes de lesa humanidad que, que como se ha visto, empieza ya a llamar la atención de los tribunales internacionales encargados de la protección del $\mathrm{DIH}$.

\section{CONCLUSIÓN}

La realidad de la terminación, o al menos la negociación de la terminación del conflicto armado en Colombia requiere la reflexión concienzuda y crítica de los desafios legales que implica su materialización.

El de la modulación de la inhabilidad política por condena judicial como acuerdo para compartir el poder con los exintegrantes de las FARC es un tema que debe ocupar un lugar cardinal en la reflexión y crítica de la implementación del Acuerdo de Paz en este punto; pues, aunque la Justicia Transicional invita a repensar la "cultura de justicia revanchista" tan arraigada en el país, no menos cierto es que estos mecanismos no son del todo conciliables con la garantía y protección del DIH que Colombia también reconoce. La estabilidad de la causal del numeral 1 del artículo 179 de la Constitución Política, como se vio a lo largo de esta investigación, ha quedado en entredicho a partir del proceso de paz. De esta manera, la posibilidad de permitir que los excombatientes de las FARC accedan al Congreso, que fue el mecanismo para distribuir el poder que se creó en esta negociación, implicó una severa modificación a esta causal.

Sin embargo, el enmarañamiento existente entre los mecanismos de justicia transicional y la participación política generado en virtud del Acuerdo de Paz y la normatividad que lo ha desarrollado requiere que está causal de inhabilidad se revise prontamente.

Esta revisión debe realizarse con la finalidad de evitar una indebida restricción de los derechos a la participación política de los excombatientes que fueron objeto de indultos por cometer crímenes menos graves o lesivos del DIH, y también para evitar desproporcionadas lesiones al principio de la igualdad politica de los demás ciudadanos colombianos.

\section{BIBLIOGRAFÍA}

Ansor, Nadine y Sabine KuRTERBACH, Institutional reforms and peace building, New York, Routledge, 2017.

DAley, Patricia, "The Burundi peace negotiations: An african experience of peace-making", Review of African Political Economy 34 (112) (2007). DOI: $10.1080 / 03056240701449729$ 
Lecka, Chandra, Olga Martin y Johana Herman, War, Conflict and Human Rights, New York, Routledge, 2016.

LóPez PARRA, Jaime, Un enfoque histórico-hermenéutico y crítico-social en psicología y educación ambiental, Medellín, Universidad Pontificia Bolivariana, 2001.

MAncebo, Ainara, "La transformación de los sistemas electorales: la reforma electoral durante la transición democrática en Sudáfrica”, Revista Latinoamericana de Politica Comparada 11 (2016). En http://repositorio.flacsoandes.edu.ec/ handle/10469/14273

Mehler, Andreas, "Peace and power sharing in Africa: a not so obvious relationship”, African Affairs 108 (2009). En https://www.jstor.org/stable/40388400

Manin, Bernard, Los principios del gobierno representativo, Madrid, Alianza, 2008.

Molano RoJAs, Andrés, “Justicia para el posconflicto: viejos y nuevos problemas en escenarios complejos”, en Andrés Molano RoJas (ed.), El posconflicto en Colombia. Reflexiones y propuestas para recorrer la transición, Bogotá, Instituto de Ciencia Política Hernán Echavarría Ológaza y Fundación Konrad Adenauer en Colombia (KAS), 2015, pp.15-23.

PItkin, Ana, The Concept of Representation, Berkeley, University of California Press, 1992.

Rey Moreno, Héctor Enrique, La inelegibilidad. Su tratamiento en el sistema jurídico colombiano, Bogotá, Grupo Editorial Ibáñez, 2008.

SÁnchez TorRes, Carlos Ariel, Derecho electoral colombiano, Bogotá, Legis, 1997.

Vives EcheverRía, José Ignacio, Tratado de derecho electoral colombiano, Bogotá, Temis, 1984.

\section{ACUERDOS}

Acuerdo de Lome, 1999, en https://peaceaccords.nd.edu/accord/ouagadougoupolitical-agreement-opa

Acuerdo de Chapultepec, 1991, en https://peaceaccords.nd.edu/accord/ouagadougou-political-agreement-opa

Acuerdo Final de Colombia, 2016, en http://www.altocomisionadoparalapaz.gov. co/procesos-y-conversaciones/Documentos\%20compartidos/24-11-2016NuevoAcuerdoFinal.pdf

\section{JURISPRUDENCIA}

144 Colombia, Consejo de Estado, Sala Plena de lo Contencioso Administrativo, sentencia de 5 de junio de 2001, radicado: AC-11861, C.P. Reinado Chavarro Buriticá, actor: Gabriel Villegas Raigoza, demandado: Luis Javier Castaño Ochoa. 
Colombia, Consejo de Estado, Sala Plena de lo Contencioso Administrativo, sentencia de 4 septiembre 2001, radicado: 11001-03-15-000-2001-0098-01(AC), C. P. Juan Ángel Palacio Hincapié, Actor: Pablo Bustos Sánchez y Carlos Valera Pérez, demandado: José Antonio Gómez Hermida.

Colombia, Corte Constitucional, Sentencia C-194 de 4 de mayo de 1995, M. P. José Gregorio Hernández Galindo.

Colombia, Corte Constitucional, Sentencia C-952 de 5 de septiembre de 2001, M. P. Álvaro Tafur Galvis.

Colombia, Corte Constitucional, Sentencia C-928 de 6 de septiembre de 2005, M. P. Jaime Araújo Rentería.

Colombia, Corte Constitucional, Comunicado 55 del 14 de noviembre de 2017.

Corte Interamericana de Derechos Humanos, Caso Castañeda Gutman vs. México, 6 de agosto de 2008, Excepciones Preliminares, Fondo, Reparaciones y Costas, Serie C, núm. 184.

Declaración Universal de los Derechos Humanos (10 de diciembre de 1948), en http://www.un.org/es/universal-declaration-human-rights /

International Criminal Court, Judgment ICC-01-05-01-08, 21 de junio de 2016, en https://www.icc-cpi.int/CourtRecords/CR2016_04476.PDF

International Criminal Court 02/11-01/11-656-Red, June 12 2014, en https:// www.icc-cpi.int/Pages/record.aspx?docNo=ICC-02/11-01/11-656-Red 